\section{UN ARTISTA INMORAL PERSEGUIDO POR LA INQUISICIÓN EN ZARAGOZA: EL PROCESO CONTRA EL ESCULTOR JOSÉ MARTÍNEZ (1647)}

AN INMORAL ARTIST PERSECUTED BY THE INQUISITION IN ZARAGOZA: THE PROCESS AGAINST THE SCULPTOR JOSÉ MARTÍNEZ (1647)

UN ARTISTE IMMORAL PERSÉCUTÉ PAR L'INQUISITION À SARAGOSSE: LE PROCESSUS CONTRE LE SCULPTEUR JOSÉ MARTÍNEZ (1647)

RESUMEN: El escultor navarro José Martínez, discípulo de Martínez Montañés en Sevilla y colaborador de Manuel Pereira en Madrid, fue perseguido por la Inquisición por blasfemia en la capital hispánica, por bigamia en Tudela y por simular ser familiar del Santo Oficio en Zaragoza. El proceso incoado en 1647 en la ciudad aragonesa, aquí estudiado, ofrece información relevante acerca de la cotidianeidad de los artistas de Zaragoza a mediados del siglo XVII, así como otros datos hasta el momento ignorados.

PALABRAS CLAVE: José Martínez del Notario; escultor; Juan Martínez Montañés; Zaragoza; Inquisición; proceso; siglo XVII.
ABSTRACT: The Navarrese sculptor José Martínez, disciple of Martínez Montañés in Seville and collaborator of Manuel Pereira in Madrid, was persecuted by the Inquisition for blasphemy in Madrid, for bigamy in Tudela and for pretending to be a member of the Holy Office in Zaragoza. The process initiated in 1647 in Zaragoza, here studied, offers relevant information about the daily life of artists established in Zaragoza in the middle years of the 17th century, as well as another data so far ignored.

KEYWORDS: José Martínez del Notario; sculptor; Juan Martínez Montañés; Zaragoza; Holy Office of the Inquition; process; 17th century.

\section{CARRETERO CALVO, Rebeca}

Universidad de Zaragoza (UZ)

Departamento de Historia del Arte Pedro Cerbuna, 12

50009 Zaragoza

rcc@unizar.es

ORCID ID: 0000-0002-1754-1597

Este estudio se ha llevado a cabo en el marco del grupo consolidado del departamento de Historia del Arte de la Universidad de Zaragoza Patrimonio Artístico en Aragón ( $\mathrm{H} 03)$, actividades de investigación subvencionadas por el Gobierno de Aragón y Fondos FEDER, 20142017.

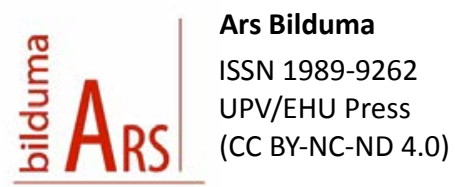

83

MOTS-CLÉS: José Martínez del Notario; sculpteur; Juan Martínez Montañés; Saragosse; Saint-Office de I'Inquisition; processus; XVIle siècle. https://doi.org/10.1387/ars-bilduma.17778 BIBLID [(2018), 8; 83-99]

Recep.: 29/04/2017 Acept.: 09/06/2017 


\section{INTRODUCCIÓN}

De entre los ciento ochenta y un procesos criminales y de fe abiertos por el Tribunal de la Inquisición del distrito de Zaragoza durante el reinado de Felipe IV custodiados en el Archivo Histórico Provincial de la capital aragonesa, ${ }^{1}$ destacamos el iniciado contra el escultor José Martínez del Notario por simular pertenecer al Santo Oficio en la ciudad del Ebro, fechado el 27 y 28 de marzo de 1647 -doc. no 1-. ${ }^{2}$ Aunque parece una causa incompleta o interrumpida pues carece de sentencia y de la habitual anotación final de los gastos de costas y minutas, sí contiene mandamiento de prisión contra el reo. El texto documental conservado constituye la cédula de apellido criminal o denuncia, un escrito que iniciaba el proceso, es decir, que servía para incoarlo y que motivaba la información sumaria. Se trata, por tanto, de un procedimiento preliminar. ${ }^{3}$ En este caso, el promotor fiscal fue Pedro de Medina Rico, que expuso los cargos imputados al reo y concluyó solicitando tanto el prendimiento del acusado como la información de lo expuesto. A continuación, se inició el

1 Han sido estudiados, junto con las relaciones de causas y algunos procesos sueltos conservados en el Archivo Histórico Nacional de Madrid, en PASTOR OLIVER, M. Ma: EI tribunal inquisitorial de Zaragoza, bajo el reinado de Felipe IV. Tesis de doctorado. Zaragoza, Departamento de Historia Moderna y Contemporánea de la Universidad de Zaragoza, 2010.

2 Este proceso ha sido recogido en la citada tesis doctoral de Marta María Pastor Oliver donde se comenta únicamente desde un punto de vista descriptivo como ejemplo para trazar la historia y los casos del tribunal inquisitorial de Zaragoza durante el reinado de Felipe IV. En consecuencia, su contenido no ha sido apurado, interpretado, ni transcrito in extenso y, por supuesto, no ha sido puesto en valor en el marco de la Historia del Arte de la Edad Moderna. Por todo ello, constituye un magnífico ejemplo de cómo un texto documental puede ser analizado de diferente modo según la disciplina que lo estudie.

3 PASTOR OLIVER, M. Ma: op. cit., p. 47. interrogatorio a los testigos, pero no al inculpado que para entonces ya había huido de la ciudad. El proceso no incluye ningún documento más.

Sin embargo, pese a estar inconclusa, esta causa resulta una fuente de primera magnitud para el estudio de la Historia social del Arte dado que aporta interesantes datos relativos a la actividad cotidiana de los artistas establecidos en Zaragoza en los años centrales del siglo XVII, a sus relaciones personales y artísticas, a su carácter personal, a su forma de actuar y a sus costumbres, así como ofrece nombres de artífices que hasta el momento eran desconocidos. Se trata de una información relevante que otras fuentes no expresan y que, en este caso, son, además, de primera mano. A esto debemos de añadir que el expediente zaragozano constituye la continuación de un proceso anterior iniciado por el Tribunal de Toledo contra el mismo escultor por blasfemia en 1644 -aunque los hechos narrados sucedieron dos años antes- y que se halla custodiado en el Archivo Histórico Nacional de Madrid. ${ }^{4}$ Posteriormente, fue completado y trasladado al Tribunal de Logroño donde al parecer se perdió, y que fue dado a conocer por José María de Azcárate en $1949^{5}$ y recordado por Cordero de Ciria en $1992 .^{6}$

4 Archivo Histórico Nacional de Madrid [AHN], Inquisición, 40, Exp. 29: Proceso de José Martínez, escultor, 1644.

5 AZCÁRATE, J. Ma de: "El escultor José Martínez", Archivo Español de Arte, XXII, 1949, p. 84.

6 CORDERO DE CIRIA, E.: “Notas sobre el escultor José Martínez, discípulo de Martínez Montañés y colaborador de Pereira, procesado por la Inquisición", Archivo Español de Arte, 258, 1992, pp. 234-235. 


\section{LOS ACTORES: EL REO Y LOS TESTIGOS}

Conocemos los datos fundamentales de la biografía de José Martínez del Notario gracias al proceso de 1644 promovido en Madrid tras la denuncia por blasfemia de Pantaleón Gómez, hermano de Manuel Pereira, ambos escultores y de origen portugués instalados en la capital hispánica. ${ }^{7}$ Martínez era natural de la localidad navarra de Aguilar -en la actualidad Aguilar de Codés-, en la Merindad de Estella, donde nació hacia 1612. Según él mismo había declarado, trabajaba como escultor desde los 16 años, primero en el taller de la calle de la Muela de Juan Martínez Montañés en Sevilla durante un año y medio, después en Granada por tiempo de tres años y medio "junto al Pilar del Toro", y luego en Madrid. En la villa y corte entró como colaborador en casa de Manuel Pereira, residiendo con el maestro en la calle de Cantarranas -actual de Lope de Vega-, aunque posteriormente Martínez trasladó su domicilio a la de Santa Isabel. ${ }^{8}$ En efecto, está documentada la presencia de un escultor llamado José Martínez como testigo del poder para testar otorgado a María González de Estrada, esposa de Pereira, en Madrid el 31 de octubre de $1639,{ }^{9}$ donde permaneció, como él mismo narró, hasta finales de 1643, o hasta comienzos de 1644, y como recordó "el amo con quien trabajava [Manuel Pereira]", según se recoge en dicho proceso. En esta última fecha huyó a su población natal, después a Pamplona, de allí a Zaragoza, y

7 Manuel Pereira era familiar del Santo Oficio probablemente desde 1635 (AGULLÓ Y СОBO, M.: "Manuel Pereira: Aportación documental", Boletín del Seminario de Arte y Arqueología, XLIV, 1978, p. 259), por lo que es posible que él mismo instara a su hermano a que denunciara a su colaborador, como se sugiere en SÁNCHEZ GUZMÁN, R.: "El escultor Manuel Pereira (1588-1683)", Cuadernos de Arte e Iconografía, t. XVII, no 33, 2008, pp. 61-62.

8 CORDERO DE CIRIA, E.: op. cit., pp. 234-235; SÁNCHEZ GUZMÁN, R.: op. cit., pp. 61-62.

9 AGULLÓ Y COBO, M.: op. cit., doc. no 22, p. 270. finalmente a Tudela (Navarra), ciudad en la que fue prendido en junio de $1644 .^{10}$

Sin embargo, el proceso zaragozano que ahora estudiamos advierte que Martínez había estado en la cárcel en una ocasión anterior a la de Tudela por bígamo, de la que se fugó. Aunque no revela en qué lugar, es probable que fuera en Navarra pues uno de los testigos -el pintor Juan Galindo de Medina, del que enseguida hablaremos- declaró ante la Inquisición que el propio escultor le había contado que se había casado con una mujer vizcaína "por fuerza", razón por la que "no quiso consumar el matrimonio". Una vez en Madrid, tuvo amistad con una viuda y que, "haviendo vuelto a su tierra le escrivia la dicha viuda sin dezir como se llamaba, y poniendole el sobre escrito a mi marido Josepe Martinez, y el a ella respondia, a mi muger fulana, pero que no se havia casado con ella". Tras esta explicación, Martínez aseguró que se trataba de una treta para disimular "por si alguno les cogia las cartas", circunstancia que ocurrió en tierras navarras, siendo denunciado por el pintor Juan de Espinosa que para entonces se encontraba en Pamplona, como luego veremos.

Después de esto, el escultor de Aguilar fue apresado en Tudela en junio de 1644, pero poco tiempo más tarde debió ser liberado puesto que antes de marzo de 1647 residía en Zaragoza en la casa del pintor Juan Galindo de Medina, situada en la calle de la Verónica, en la parroquia de San Miguel.

El 28 de marzo de 1647 el primer testigo en personarse en el palacio de la Aljafería, sede del Tribunal del Santo Oficio de Zaragoza, ante la presencia del inquisidor Pedro Allande y Mon para responder a sus preguntas fue el pintor Bartolomé Roberto, ${ }^{11}$ un artista desconocido para la historiografía

10 AHN, Inquisición, 40, Exp. 29: Proceso de José Martínez, escultor, 1644, f. 12.

11 Al final de su intervención firma como Bartolomé Roberto Zastrón. 
artística hasta este momento. Gracias a esta causa sabemos que Bartolomé Roberto era natural de Calatorao (Zaragoza) y que tenía 30 años de edad, por lo que debió nacer hacia 1617. En realidad, poco pudo decir del imputado pero lo suficiente como para que resulte de interés. En primer lugar, reveló que el escultor, de quien ignoraba su nombre, le estaba haciendo "una hechura de Niño Jesus" y que residía en la casa del pintor Juan de Medina [sic] en la calle de la Verónica, "en el callejon que no tiene salida". A continuación, manifestó que cuatro o cinco días atrás, en casa de dicho pintor y delante del sastre Antonio Fernando, que vivía junto al colegio de las Vírgenes de Zaragoza, el investigado afirmó que era familiar del Santo Oficio jactándose de que una noche, mientras se dirigía a casa de una mujer, fue interceptado por la justicia civil que estaba de ronda. Para librarse de ella, aseguró que pertenecía a la Inquisición y que iba a visitar a una sospechosa, adonde la milicia lo acompañó quedándose esperando en la puerta. Poco después, el escultor abandonó la vivienda aclarando que "no havia hallado lo que buscaba".

El breve interrogatorio nos lleva a plantear varias cuestiones: la primera, que José Martínez no disponía de casa propia en Zaragoza, ${ }^{12}$ sino que vivía en la de un pintor. ¿Acaso trabajaba con él en alguna obra concreta? Lo desconocemos, pero lo que sí podemos asegurar es que para entonces el escultor estaba realizando una imagen del Niño Jesús para Bartolomé Roberto. Por este motivo, es posible que Medina únicamente alquilara una habitación a Martínez como medio económico. No obstante, como enseguida comprobaremos, Galindo de Medina reconocerá ante la Inquisición ser natural de Madrid, por lo que es posible que hubieran entrado en contacto por algún asunto carente de carácter artístico, aunque por razones obvias el pintor decidiera no mencionarlo.

12 Hecho ya destacado en PASTOR OLIVER, M. Ma: op. cit., p. 242.
Antes de avanzar queremos detenernos un poco más en la escultura que José Martínez estaba llevando a cabo para Bartolomé Roberto. Pese a que no se indica ningún rasgo de la imagen, su sola alusión incita a preguntarnos cómo sería y si seguiría las características de las que Martínez Montañés había creado en Sevilla, como el famoso Niño Jesús de la iglesia del Sagrario de 1606, obra que establece la versión definitiva de esta popular iconografía andaluza a la vez que constituye la cumbre de la representación del tema. ${ }^{13}$ En este sentido, cabe destacar que los biógrafos de Manuel Pereira proponen que la influencia andaluza -tanto sevillana como granadina- detectada en la producción del portugués de la década de 1630 podría provenir del propio Martínez del Notario, ${ }^{14}$ como ya apuntamos, su colaborador durante varios años en su estancia madrileña. Ante ello, sería interesante indagar en el futuro si sucedió lo mismo durante su establecimiento en Zaragoza, es decir, si el estilo aprendido con el gran Martínez Montañés repercutió, y si lo hizo en qué grado, a su paso por la capital aragonesa.

El segundo y último testigo resulta mucho más explícito. Aunque el documento lo denomina como Juan de Medina, al final del texto firmó como Juan Galindo de Medina. Este pintor, nacido en Madrid hacía

13 RECIO MIR, Á.: "La difusión de los modelos montañesinos del Niño Jesús: causas de una producción seriada", en RAMOS SOSA, R. (coord. y dir.): Actas del coloquio internacional el Niño Jesús y la infancia en las artes plásticas, siglos XV al XVII. IV Centenario del Niño Jesús del Sagrario, 1606-2006, Sevilla, Archicofradía del Santísimo Sacramento del Sagrario de la Catedral de Sevilla, 2010, pp. 261-288; BARTOLOMÉ GARCíA, F. R.: "Un Niño Jesús del círculo de Martínez Montañés en Vitoria", Ars Bilduma, 4, 2014, pp. 27-35; y BARTOLOMÉ GARCíA, F. R.: "Niños montañesinos en Álava", Ars Bilduma, 5, 2015, pp. 45-63.

14 URREA, J.: "Introducción a la escultura barroca madrileña. Manuel Pereira", Boletín del Seminario de Arte y Arqueología, XLIII, 1977, pp. 262 y 265; URREA, J.: "Cano y Pereira contrastados", en Symposium internacional. Alonso Cano y su época, Granada, Junta de Andalucía, 2002, p. 344; y SÁNCHEZ GUZMÁN, R.: op. cit., pp. 48-49. 
cincuenta y dos años -es decir, en 1595 aproximadamente-, era vecino de Zaragoza "de beintisiete años a esta parte" -desde 1620-, donde fijó su residencia en la calle de la Verónica, "en la plazeta de la Perera". En primer lugar, el artista expresó que el reo alardeaba de pertenecer al Santo Oficio de la Inquisición del distrito de Logroño y de poseer su título, "si bien este no se le ha visto". A continuación, relató el mismo suceso con la justicia civil que su antecesor. Medina aseguró que todo ello aconteció ante la presencia de los dos criados de Martínez, uno llamado Juan y otro Agustín, de los que ignoraba sus apellidos, pero que sabía que el primero seguía al servicio del escultor, mientras que el segundo "entiende que esta ahora en la villa de Madrid".

Además, prosiguió explicando que con anterioridad a este hecho el escultor "vivia y trabajaba" con el ensamblador Sebastián de Ruesta, "junto al convento de Santa Fe de esta ciudad" - situado en la actual plaza de Salamero, desaparecido a finales del siglo XIX-, "frente al Meson de la Alfondiga", donde ya se había jactado con soberbia de formar parte del Santo Oficio. En este sentido, su abuso llegó hasta tal punto que un vendedor de pescado de la plaza del Pilar se vio obligado a regalar "sardinetas" a Martínez por la única razón de pregonar ser miembro de la Inquisición, sin necesidad de demostrarlo. ${ }^{15} \mathrm{Si}$ bien es cierto que por aquel entonces se documentan algunos casos semejantes en la ciudad, ${ }^{16}$ éste es el único, hasta el momento, relativo a un artista. ${ }^{17}$ La pertenencia al Santo

15 Cuestión destacada asimismo en PASTOR OLIVER, M. Mạ: op. cit., pp. 326 y 332-333.

16 Como el del tejedor de tafetanes y terciopelo Jaime López que para tratar de evitar el embargo de unas deudas fingió ser miembro del tribunal inquisitorial, o el de Jerónimo Abadía que amenazó a un grupo de personas, o el del notario Juan Bayot que afirmó pertenecer a la Inquisición para desempeñar su oficio en Valjunquera sin ningún inconveniente, según se expresa en ibid., pp. 332-333.

17 En la Comunidad de Calatayud tenemos constancia de varios artífices que simultanearon su práctica artística con el servicio a la Inquisición, como es el caso del
Oficio constituía un privilegio en la sociedad del Antiguo Régimen puesto que beneficiaba a sus integrantes con autoridad y protección, aunque no con sueldo, y les distinguía permitiéndoles portar armas, su cruz en el pecho -que el propio Martínez dijo tener que recoger en la Platería- u ocupar ciertos asientos tanto en ceremonias públicas como en las iglesias. Los miembros de la Inquisición eran temidos y respetados pero también odiados por exceder en ocasiones los límites de su poder, ${ }^{18}$ que es justamente lo que este escultor hacía.

Sin embargo, aunque él, en efecto, no lo era, varios miembros de la familia Martínez del Notario oriundos de Aguilar (Navarra) sí llegaron a serlo. El Archivo Histórico Nacional de Madrid conserva el expediente de Miguel Martínez del Notario, natural de Aguilar (Navarra), para convertirse en ministro del Tribunal de la Inquisición de Logroño en 1599. ${ }^{19}$ El 9 de agosto de ese año el Santo Oficio inició los trámites para obtener información sobre su genealogía y poder comprobar su limpieza de sangre, ${ }^{20}$ indispensable para ser familiar. La investigación, llevada a cabo los días 11 y 12 de agosto por el comisario del Santo Oficio de Elciego (Álava) Pedro de Irazo, se basó en el interrogatorio a seis habitantes de Aguilar-dos clérigos beneficiados, un escribano real y otros tres vecinos cuyo oficio no se especifica- que declararon que para entonces Miguel Martínez contaba con 28 años, que sus padres eran Pedro Martínez del Notario, ya difunto, y

escultor Lope García de Tejada (CRIADO MAINAR, J.: La escultura romanista en la Comarca de la Comunidad de Calatayud y su área de influencia. 1589-1639. Calatayud, Centro de Estudios Bilbilitanos de la Institución «Fernando el Católico», 2013, pp. 279281).

18 PASTOR OLIVER, M. Mạ: op. cit., pp. 2 y 6.

19 Lamentablemente, no estamos en disposición de establecer, de momento, el grado de parentesco entre Miguel Martínez del Notario y José Martínez del Notario.

20 AHN, Inquisición, 1313, Exp. 12: Información genealógica de Miguel Martínez del Notario, 1599. 
María de Antoñana, sus abuelos paternos Pedro Martínez del Notario y María Sanz, y los maternos Juan de Antoñana y María de Erenchun. Los entrevistados afirmaron que Miguel se encontraba desde hacía nueve años al servicio del inquisidor Pedro de Zamora, ${ }^{21}$ además de que dos de sus hermanos ya eran familiares del Santo Oficio, así como su primo, el doctor Miguel de Ayala, que era inquisidor de Murcia. Tras la indagación, el veredicto fue finalmente positivo para el candidato.

Regresando al testimonio del pintor Galindo de Medina, éste aún añadió que, "habra cosa de dos meses poco mas o menos estando en su casa", Martínez había reconocido, "calentandose a la chimenea", que hacía diez años que no se confesaba y que la Inquisición le había apresado en dos ocasiones "por casado dos vezes", tras lo que le narró su matrimonio "a la fuerza" con una vizcaína y sus escarceos amorosos con una viuda en Madrid ya comentados.

Según apuntamos anteriormente, desconocemos si Medina y Martínez habían tenido algún tipo de contacto antes de 1647, pero lo que sí podemos asegurar es que el pintor llegó a Zaragoza antes de lo que recordó ante el Santo Oficio. De hecho, está documentada su presencia en la ciudad del Ebro el 16 de diciembre de 1617 cuando asistió a la capitulación matrimonial del también pintor Martín de Ortiz con Polonia Aznar, en compañía del pintor Pascual de Arbisa y de su esposa María Petroche. ${ }^{22}$ Arbisa falleció apenas dos años más tarde, momento en el que

21 Sobre el Tribunal de la Inquisición de Logroño en esta época puede consultarse SIMÓN DÍAZ, J.: “La Inquisición de Logroño (1580-1600)”, Berceo, 6, 1948, pp. 83-96.

22 Archivo Histórico de Protocolos Notariales de Zaragoza [AHPZ], Domingo Montaner, 1617, ff. 815-818, (Zaragoza, 16-XII-1617). Su regesta en LANASPA MORENO, Ma Á.: Las artes en Aragón en el siglo XVII según el Archivo de Protocolos Notariales de Zaragoza. De 1616 a 1618. Zaragoza, Institución «Fernando el Católico», 2005, p. 183. Disponible online en http://ifc.dpz.es/recursos/publicaciones/25/15/_ebook.pdf (Consultado el su mujer entregó 1.900 sueldos a Galindo de Medina por una comanda. ${ }^{23}$ Diez años más tarde, el 7 de julio de 1629, el pintor Juan Galbán nombró a Galindo de Medina para que reconociera y tasara la obra mural que había realizado en la iglesia del convento de la Concepción de Épila (Zaragoza), ${ }^{24}$ de lo que se desprende que, pese a que haya pasado prácticamente desapercibido para la historiografía, era un artista reconocido en la ciudad.

\section{LOS ARTISTAS CITADOS EN EL PROCESO}

Además de los pintores que actuaron como testigos, los nombres de otros dos artistas aparecen recogidos en la causa inquisitorial cuyas personalidades todavía están pendientes de un estudio en profundidad. Se trata de Sebastián de Ruesta y de Juan de Espinosa. Sebastián de Ruesta era hijo del tornero Francisco de Ruesta, ya fallecido en diciembre de $1631,{ }^{25}$ y de Francisca Pastor. Desconocemos con certeza su localidad natal,

16/03/2017).

23 AHPZ, Diego Francisco Moles, 1619, f. 215 v., (Zaragoza, 6-III-1619). Su regesta en MIGUEL LOU, G. de: Las artes en Aragón en el siglo XVII según el Archivo de Protocolos Notariales de Zaragoza. De 1619 a 1621. Zaragoza, Institución "Fernando el Católico», 2005, p. 28. Disponible en: http://ifc.dpz.es/recursos/publicaciones/23/89/_ebook.pdf (Consultado el 16/03/2017)

24 LÁZARO SEBASTIÁN, F. J.: "El Capítulo Eclesiástico de Épila en el Archivo de Protocolos Notariales de La Almunia de Doña Godina", en Archivo Ducal de Hijar. Archivo Abierto, p. 19. Disponible online en http://www.archivoducaldehijararchivoabierto.com/articulos/ad008.pdf (Consultado el 11/03/2017).

25 No era hijo del arquitecto barbastrense Pedro Ruesta como propuso la Gran Enciclopedia Aragonesa (BOLOQUI LARRAYA, B.: voz "Ruesta, Los", en Gran Enciclopedia Aragonesa, Zaragoza, UNALI, 1981, t. XI, p. 2944), ni del piloto mayor de la Casa de Contratación de Sevilla Francisco de Ruesta como señaló Llaguno y Amirola (LLAGUNO Y AMIROLA, E.: Noticias de los arquitectos y arquitectura en España Madrid, Imprenta Real, 1829, t. IV, p. 51), del que, sin embargo y como veremos, era 
pero es posible que fuera natural de Barbastro (Huesca). El 9 de diciembre de 1631 firmó su contrato de aprendizaje con el ensamblador, entallador y carpintero Tomás Lagunas ${ }^{26}$ en Zaragoza por tres años, documento que transcribimos debido a la importancia del artista -doc. nㅇ 2-. Tras concluir su formación, aparece trabajando tanto en Zaragoza como en Huesca. En la ciudad del Ebro participó en la creación de los túmulos llevados a cabo en octubre de 1646 con motivo del repentino fallecimiento del príncipe heredero Baltasar Carlos, ${ }^{27}$ época en la que, según informa el proceso

hermano.

26 Tomás Lagunas estaba casado con Ana Francisca Barrera con la que contrajo matrimonio en 1616. Véase LANASPA MORENO, Ma Á.: Op. cit., pp. 18, 26 y 66; y JODRÁ ARILLA, G.: Las artes en Aragón en el siglo XVII según el Archivo de Protocolos Notariales de Zaragoza. De 1634 a 1636, Zaragoza. Institución «Fernando el Católico», 2007, p. 72. Disponibles en http://ifc.dpz.es/recursos/publicaciones/25/15/_ebook.pdf y http://ifc.dpz.es/recursos/publicaciones/26/67/_ebook.pdf (Consultado el 23/03/2017). Asimismo, es citado como mazonero en un documento de comanda recogido en ibid., p. 143. La obra documentada de Lagunas se encuentra en LANASPA MORENO, Ma Á.: op. cit., p. 133 [retablo del Santo Cristo para el mercader zaragozano Pedro Gabín], y en GRANADOS BLASCO, Ma del C.: Las artes en Aragón en el siglo XVII según el Archivo de Protocolos Notariales de Zaragoza. De 1637 a 1639. Zaragoza, Institución «Fernando el Católico», 2007, pp. 147-148 [peana para la Virgen del Rosario de la iglesia de Pozuelo (Zaragoza)], y 149 [retablo para la parroquial de Villanueva de Huerva (Zaragoza)], http://ifc.dpz.es/recursos/publicaciones/26/68/_ebook.pdf (Consultado el 23/03/2017). Al año siguiente de tomar a Ruesta, el joven de Épila Francisco Casales entró como nuevo aprendiz en el taller de Lagunas, en LONGÁS LACASA, Ma Á.: Las artes en Aragón en el siglo XVII según el Archivo de Protocolos Notariales de Zaragoza. De 1631 a 1633. Zaragoza, Institución "Fernando el Católico», 2006, p. 209. Disponible en: http://ifc.dpz.es/recursos/publicaciones/25/76/_ebook.pdf (Consultado el 23/03/2017). Su testamento, otorgado el 18 de febrero de 1633, se referencia en ibid., p. 311. Igualmente, tenemos noticias de que Tomás Lagunas estuvo preso en la cárcel real al menos en septiembre de 1618, sin especificar el motivo, como se documenta en LANASPA MORENO, Ma Á.: op. cit., p. 259.

27 LLAGUNO Y AMIROLA, E.: op. cit., pp. 50-51; y ESTEBAN LORENTE, J. F.: “Una aportación al arte provisional del barroco zaragozano: los capelardentes reales", en Francisco inquisitorial, José Martínez "vivia y trabajaba" con él. En la capital oscense la traza de Ruesta ganó el concurso público promovido en 1648 para la construcción del nuevo retablo mayor de la basílica de San Lorenzo. Dos años después, todavía seguía recibiendo pagos por el diseño. ${ }^{28}$

Por entonces, Sebastián de Ruesta y su esposa Isabel de Correa, con la que no tuvo descendencia, ${ }^{29}$ abandonaron para siempre tierras aragonesas para establecerse en Sevilla. Probablemente, este traslado pudo estar motivado porque su hermano Francisco residía allí desde al menos el 22 de junio de 1633, momento en el que éste fue designado piloto mayor de la Casa de la Contratación. ${ }^{30}$ Además, el 25 de diciembre de 1645 recibió el nombramiento de arqueador y medidor de naos de la misma institución. ${ }^{31}$

El 30 de marzo de 1650 Sebastián de Ruesta fue elegido Maestro Mayor del Alcázar sevillano, cargo que ocupó hasta su fallecimiento el 27 de noviembre de 1669 no sin protagonizar enfrentamientos con el personal del edificio debido a su carácter fuerte e irascible. En el acto de juramento, Ruesta aseguró que era "maestro examinado en ambas artes de albañileria y carpinteria" en la ciudad de Zaragoza. ${ }^{32}$ El 30 de junio de 1652 fue

Abbad Ríos: a su memoria, Zaragoza, Departamento de Historia del Arte de la Universidad de Zaragoza, 1973, pp. 43-45.

28 PALLARÉS FERRER, Ma J.: La pintura en Huesca durante el siglo XVII. Huesca, Instituto de Estudios Altoaragoneses, 2001, pp. 80 y 204.

29 Como se expresa en una copia de una de las cláusulas de su testamento fechado en 1686 en la que nombra como su heredero a Francisco Escartín. En Archivo General de Indias [A.G.I], Contratación, 5584, № 4.

30 A.G.I, Contratación, 5785, L. 1, ff. 133-135 v.

31 Ibid., ff. 251-252.

32 MARÍN FIDALGO, A.: El Alcázar de Sevilla bajo los Austrias. Sevilla, Guadalquivir, 1990, vol. 2, pp. 601-608. 
nombrado cosmógrafo de la Casa de la Contratación. ${ }^{33} \mathrm{~A}$ partir de entonces él mismo se intitulaba como "arquitecto, maestro mayor de los Reales Alcazares de Sevilla, cosmografo y fabricador de instrumentos matematicos por Su Majestad para la Carrera de las Indias". ${ }^{34}$ Dos años después, Sebastián y su hermano Francisco mantuvieron un desencuentro debido a que el segundo acusó al primero de haber incluido errores en un mapa que él, como piloto mayor, no podía ratificar. ${ }^{35}$

Además de encargarse de dirigir las obras de mantenimiento y pequeñas intervenciones del Alcázar de Sevilla, ${ }^{36}$ a partir de 1655 llevó a cabo otros trabajos en la capital hispalense como el diseño de la iglesia del convento del Espíritu Santo en ese mismo año ${ }^{37}$ o la traza del sagrario efímero de la catedral en $1662,{ }^{38}$ entre otras intervenciones. ${ }^{39}$

33 A.G.I., Contratación, 5785, L. 2, ff. 28-29 v.

34 MARÍn FIDALGO, A.: op. cit., p. 602; y FONSECA COUTO GOMES PEREIRA, M. A. da (ed.): Obras do Barão do Rio Branco IV: questões de limites Guiana francesa segunda memória. Brasilia, Fundação Alexandre de Gusmão, 2012, p. 84.

35 A.G.I., Contratación, 850, no 8. Sobre esta figura véase PULIDO RUBIO, J.: El Piloto Mayor de la Casa de la Contratación de Sevilla: pilotos mayores del siglo XVI. Sevilla, Centro Oficial de Estudios Americanistas de Sevilla, 1923.

36 Según estudió Ana Marín, Ruesta no destacó por la ejecución de obras importantes en el Alcázar. Véase MARÍN FIDALGO, A.: op. cit., p. 608.

37 LLAGUNO Y AMIROLA, E.: op. cit., p. 50; MARÍN FIDALGO, A.: op. cit., p. 602; y FERNÁNDEZ ROJAS, M.: "El convento del Espíritu Santo de Sevilla, vulgo de los Menores, de la Orden de Clérigos Regulares Menores", Laboratorio de Arte, 19, 2006, pp. 197 y 199.

38 RECIO MIR, Á.: "Aquella segunda fábrica que ha de estar en lo interior de la otra: Los proyectos de tabernáculo para el sagrario de la catedral de Sevilla y su realización efímera en 1662", Archivo Español de Arte, t. LXXVI, no 301, 2003, pp. 55-70.

39 MARÍN FIDALGO, A.: op. cit., pp. 602-603.
Por el contrario, la alusión a Juan de Espinosa en el proceso contra José Martínez del Notario no resulta fácil de dilucidar debido a la existencia en España de varios pintores con este nombre durante la primera mitad del siglo XVII. ${ }^{40}$ Pese a que el profesor Gutiérrez Pastor intentó hace años desligar las biografías de algunos de estos artistas homónimos, la información que ahora manejamos no concuerda de manera exacta con ninguno de ellos. No obstante, está bastante próxima a la figura del pintor Juan de Espinosa que, como certifica Ismael Gutiérrez, declaró ser natural de Pamplona en un documento fechado en 1645, donde al parecer pudo nacer entre 1615 y 1620, y que falleció en el monasterio de San Millán de la Cogolla (La Rioja) en 1653. ${ }^{41}$

El pintor Juan de Espinosa que denunció al escultor José Martínez por bígamo en tierras navarras nació, según la declaración de Juan Galindo de Medina, en Zaragoza, y era "hijo de Espinosa el pretinero". Para entonces, esto es, hacia 1645, Espinosa se encontraba en Pamplona -dato que coincide a la perfección con el pintor documentado por Gutiérrez Pastor-, mientras que en el momento del interrogatorio -marzo de 1647- se encontraba en Calahorra (La Rioja). En efecto, entre 1635 y 1639 está documentado en Zaragoza un guarnicionero llamado Juan de Espinosa casado con Catalina de Gracia, y padres de Catalina de Espinosa, esposa del ensamblador y carpintero Pedro Bautista Llofrio. ${ }^{42}$

40 GUTIÉRREZ PASTOR, I.: "Juan de Espinosa y otros pintores homónimos del siglo XVII", en Príncipe de Viana. Primer Congreso General de Historia de Navarra. Historia del arte Anejo no 11, Pamplona, Gobierno de Navarra, 1988, pp. 209-228.

41 Id., p. 216.

42 La capitulación matrimonial de Catalina de Espinosa y Pedro Llofrio se encuentra en AHPZ, Miguel Juan Montaner, 1635, ff. 1.356 v.-1.363 v., (Zaragoza, 5-VII-1635). Su regesta en JODRÁ ARILLA, G.:op. cit., p. 187. Disponible online en http://ifc.dpz.es/recursos/publicaciones/26/67/_ebook.pdf (Consultado el 17/03/2017). Más documentos relativos al matrimonio y al guarnicionero Espinosa en 
La presencia del pintor Juan de Espinosa en Calahorra no era conocida hasta este momento. De hecho, según afirma el profesor Gutiérrez Pastor, desde la llegada de Espinosa a La Rioja hasta su primera obra allí documentada existía una laguna cronológica de tres años entre 1646 y $1648,{ }^{43}$ vacío que gracias a este dato puede comenzar a colmarse.

No obstante, encontramos de nuevo a Juan de Espinosa en Zaragoza el 3 de abril de 1660 aceptando como su aprendiz a Diego Sancho por dos años $^{44}$ y el 1 de octubre de 1671 otorgando su testamento, ${ }^{45}$ por lo que es evidente que resulta imposible que se trate del mismo Espinosa fallecido en San Millán de la Cogolla en 1653.

\section{CONCLUSIONES}

Sin faltar a la verdad podemos asegurar que la práctica totalidad de la biografía del escultor José Martínez del Notario la conocemos a través de procesos inquisitoriales. En el primero, incoado en Madrid en 1644, el propio imputado ofrecía sus datos básicos y revelaba haber sido discípulo de Juan Martínez Montañés en Sevilla durante un año y medio y haber residido en Granada después por tres años y medio. En la villa y corte

ídem, pp. 189, 214, 236 y 272 [aunque su nombre ha sido transcrito por José]. La joven Catalina falleció cuatro años más tarde, como se documenta en GRANADOS BLASCO, Ma del C.:op. cit., p. 228. Disponible en http://ifc.dpz.es/recursos/publicaciones/26/68/_ebook.pdf (Consultado el 17/03/2017).

43 GUTIÉRREZ PASTOR, I.: op. cit., p. 217.

44 BRUÑÉN IBÁÑEZ, A. I., CALVO COMÍN, Mạ L., y SENAC RUBIO, Mạ B.: Las artes en Zaragoza en el tercer cuarto del siglo XVII (1655-1675). Estudio documental. Zaragoza, Institución «Fernando el Católico», 1987, pp. 256-257.

45 Id., p. 267 trabajó junto al escultor portugués Manuel Pereira hasta finales de 1643 o comienzos de 1644, momento en el que huyó de la justicia hasta ser detenido en Tudela en 1645 debido a su carácter pendenciero, soberbio y falto de moral, a lo que debemos añadir que, según afirmaron los testigos, consumía demasiado alcohol con frecuencia. El segundo proceso, abierto en Zaragoza en marzo de 1647, aquí estudiado, completa su semblanza revelando que formó parte del taller de Sebastián de Ruesta poco antes de que este último marchara a Sevilla donde se convirtió en Maestro Mayor del Alcázar, cosmógrafo, arquitecto y creador de instrumentos matemáticos. Asimismo, sabemos que Martínez residió en casa del pintor de origen madrileño Juan Galindo de Medina donde es probable que se ganara la vida confeccionando imágenes escultóricas como la del Niño Jesús que realizaba por aquel entonces para Bartolomé Roberto, un desconocido pintor nacido en Calatorao y afincado en la capital aragonesa.

Pese a todo ello, José Martínez debía ser un buen escultor. El hecho de que se baraje la hipótesis de que fuera él el encargado de transmitir las características de la escultura andaluza que se detectan en la producción artística de Pereira lo convierte en un artífice de sólida formación y personalidad creadora. Sin embargo, la Inquisición no persiguió su arte, ${ }^{46}$ sino a él como persona. Tal y como advirtió el profesor Bustamante, en la mayoría de los casos el Santo Oficio procesó a algunos artistas por asuntos

46 No obstante, se conocen casos en los que el Santo Oficio prohibió obras de arte porque no mostraban con claridad el mensaje católico. Véase PINTO CRESPO, V.: "La actitud de la Inquisición ante la iconografía religiosa. Tres ejemplos de su actuación (1571-1665)", Hispania Sacra, vol. XXXI, no 61-64, 1978-1979, pp. 297-300; VELANDIA ONOFRE, D. Hacia una teología de la imagen. Mística, oratoria y pintura en la España del Siglo de Oro. Tesis de doctorado. Barcelona, Universitat de Barcelona, 2014, p. 65; y CARRETERO CALVO, R.: "Sonidos en la pintura barroca española", en RODRÍGUEZ, G., y CORONADO, G. (dirs.): Paisajes sensoriales: Sonidos y silencios de la Edad Media, Mar del Plata, Universidad Nacional de Mar del Plata, 2016, pp. 348-352. 
de fe o motivados por odios particulares, pero no por su obra, como les sucedió a escultores de renombre como Esteban Jamete o Pompeo Leoni ${ }^{47}$ o al pintor Gabriel Ximénez Donoso. ${ }^{48}$ A esta lista debemos sumar el nombre de José Martínez del Notario que, como hemos podido comprobar, fue perseguido por el tribunal inquisitorial no en una, sino en varias de las localidades donde se estableció.

No queremos concluir sin reiterar una vez más que este proceso inquisitorial constituye una fuente de primer orden desde el punto de vista de la Historia social del Arte pues desvela las relaciones personales y profesionales entre distintos artistas, descubre su forma de vida y sus costumbres, así como refleja aspectos que a través de ningún otro texto documental hubiéramos podido conocer revelando de este modo un fragmento de cotidianeidad de la Zaragoza de mediados del siglo XVII.

47 BUSTAMANTE GARCíA, A.: "El Santo Oficio de Valladolid y los artistas", Boletín del Seminario de Estudios de Arte y Arqueología, 61, 1995, pp. 456-457. Acerca de la relación entre el Santo Oficio y el arte véase CORDERO DE CIRIA, E.: "Arte e Inquisición en la España de los Austrias", Boletín del Museo e Instituto "Camón Aznar», 70, 1997, pp. 29-86; MARÍAS, F.: "El problema de los artistas conversos en el Siglo de Oro", en MATA INDURÁIN, C., y MORÓZOVA, A. (eds.): Temas y formas hispánicas: arte, cultura y sociedad, Pamplona, Servicio de Publicaciones de la Universidad de Navarra, 2015, pp. 241-262; y FRANCO LLOPIS, B., y RUSCONI, S.: "Sobre pinturas deshonestas, lienzos y naipes protestantes. Tres documentos inquisitoriales vinculados a la censura y tráfico de imágenes heréticas en el mundo hispánico del siglo XVI", Manuscrits. Revista d'Història Moderna, 33, 2015, pp. 97-118.

48 CORDERO DE CIRIA, E.: "Proceso inquisitorial contra Gabriel Ximénez Donoso, pintor", Archivo Español de Arte, 266, 1994, pp. 171-173. 


\section{ANEXO DOCUMENTAL}

\section{Documento no 1}

1647, marzo, 27. Zaragoza

Proceso inquisitorial iniciado contra el escultor José Martínez del Notario por simular pertenecer al Santo Oficio en Zaragoza. Se incluye el interrogatorio a dos testigos: el pintor Bartolomé Roberto, natural de Calatorao pero afincado en la ciudad del Ebro, y el pintor Juan Galindo de Medina, nacido en Madrid y residente en la capital aragonesa.

Archivo Histórico Provincial de Zaragoza, Inquisición, Caja 124/14: José Martínez del Notario, escultor, vecino de Zaragoza. 1647, marzo, 27, s. f.

-Citado en PASTOR OLIVER, M. Mã : El tribunal inquisitorial de Zaragoza, bajo el reinado de Felipe IV. Tesis de doctorado. Zaragoza, Departamento de Historia Moderna y Contemporánea de la Universidad de Zaragoza, 2010, pp. 241-242, 326, 332-333, 423 y 433.

\section{[f. 1] Çaragoza. 1647.}

Jactancia de ser familiar.

El Fiscal del Santo Oficio contra Josef Martinez, escultor, vecino de Çaragoza.

\section{[f. 2] Presentada en 27 de março [de] 1647.}

Señores Lezacta, Allande.

Que se reciba informacion a tenor de esta peticion.

El doctor don Pedro de Medina Rico, Promotor Fiscal deste Santo Tribunal de la Fe Inquisicion de este Reyno de Aragon como mejor aya lugar ha de recibo, digo que a mi noticia es venido que Joseph Martinez [del] Notario, de officio escultor, vecino de la ciudad de Caragoça, en la calle de la Varonica [sic], en casa de Juan de Medina, pintor, en injuria, agravio y grave daño deste Santo Tribunal y de sus ministros y en menosprecio de la rectitud y justicia que vuestra señoria administra de mucho tiempo a esta parte y en muchas ocasiones a dicho y afirmado [entre líneas: falsa y maliciosamente] que es ministro y familiar deste Santo Tribunal, y como tal a hecho tratarse en muchas ocasiones y de muchas personas, en especial con las justicias desta ciudad y de otras partes que, encontrandolo a deshoras y en lugares sospechosos y con armas prohibidas y queriendole por ello prender, a dicho y afirmado que es ministro deste Santo Officio y que iba a una diligencia del y que requeria a las dichas justicias le fuesen acompañando y dando auxilio, el qual le ofrecieron iendo en su compañia, y el dicho reo se fue en esta forma a casa de una muger a quien tratava deshonestamente $y$, dexando la justicia a la puerta, se entro el dicho reo con la dicha muger y saliendo despues dixo que no avia hallado nada de lo que iba a buscar y desto y otras semejantes acciones se ha jactado y alabado en muchas ocasiones y delante $[f .2 \mathrm{v}$.] de muchas personas en grave enjuria deste Sancto Tribunal y para que el dicho reo sea castigado y sea a el escarmiento y a otros exemplo.

A vuestra señoria pido y suplico mande recibir informacion sumaria y con el secreto necesario a el tenor deste pedimiento y de las personas contenidas en este memorial que presenta y de las demas que yo nombrare y hecha en la parte que baste y no en mas, mande librar y libre su mandamiento de presion contra el dicho Joseph que por eso protesto acusarle en forma que para ello, et cetera. Pido justicia y juro en forma,

[Suscripción autógrafa: Pedro de Medina Rico.]

\section{[f. 3] En Çaragoza. Año 1647.}

El señor Promotor Fiscal del Santo Offizio contra Josepe Martinez del Notario, escultor.

[f. 4] En el real palacio de la Aljaferia de Çaragoza a veinte y ocho dias del mes de marzo de mil seiscientos quarenta y siete años, estando el señor inquisidor licenciado don Pedro Allande y Mon en el segundo secreto donde asiste por 
ocurrencia de negocios en su audiencia de la mañana, parecio siendo llamado y juro en forma de vida de derecho dezir verdad y guardar secreto:

Bartolome Roberto, vezino de Çaragoza, natural de Calatorau [sic], de edad que dixo ser de treinta años, de offizio pintor.

Preguntado si sabe o sospecha la causa porque ha sido llamado a este Santo Offizio, dixo que no la sabe de cierto, pero que presume ha sido llamado para dezir y manifestar a este Santo Offizio que oyo dezir a un escultor cuio nombre y apellido no sabe mas de que vive en esta ciudad, y a este le haze una hechura de Niño Jesus y vive en casa de Juan de Medina, pintor, vezino de esta ciudad, en la calle de la Veronica, en callejon que no tiene salida, habra quatro o cinco dias le dixo estando en casa del dicho Medina en presencia de otro hombre que se llama [subrayado en el original: Antonio Fernando de offizio sastre que vive al lado del] collegio de las Virgenes de esta ciudad [al margen: este afirmo el reo que era familiar del Santo Officio], que el era familiar del Santo Officio y que una noche, sin dezir en que dia, estando en esta ciudad habia encontrado a la justicia de ronda, y habiendole reconocido [subrayado en el original: y dicho que se tuviese a la justicia], [al margen: fingiose con la justicia ministro del Santo Officio y le requirio le diese auxilio y se llebo a la justicia a casa de su amiga] el habia respondido que se tuviera a la Inquisicion y que el yba a cierta casa de esta ciudad a hazer una] diligencia por orden de este Santo Offizio y que los dichos [f. $4 \mathrm{v}$.] ministros de justicia le habian acompañado a una casa que no le dixo a este qual era ni de quien, mas de que era de una muger sospechosa. Sin dezir como se llamaba y haviendo entrado en ella, volbio a salir de alli a un rato, y diziendo no havia hallado lo que buscaba, despidio los dichos ministros y se fueron.

Item dize oyo dezir al dicho Juan de Medina, pintor, que el dicho escultor dezia que era ministro de este Santo Offizio y que lo dezia en otras muchas partes, y esto es lo que sabe y tiene que dezir y para que presume ha sido llamado y que de esta materia ni de otra que toque a este Santo Offizio no tiene mas que dezir, y esta es la verdad por el juramento que tiene hecho y se afirmo en ello, fuele leido y dixo que estaba bien escrito y lo firmo.

Paso ante mi, Juan Jaime Esporrin.

\section{[f. 5 en blanco]}

[f. 6] En el real palacio de la Aljaferia de Caragoza a beinte y ocho dias del mes de marzo de mil seiscientos quarenta y siete años, estando el señor inquisidor licenciado don Pedro Allande y Mon en el segundo secreto donde asiste solo por ocurrencia de negocios en su audencia de la mañana, parezio siendo llamado y juro en forma de vida de derecho dezir verdad y guardar secreto:

[Al margen: Testigo 2o.] Juan de Medina, natural de la villa de Madrid y vezino de Caragoza de beintisiete años a esta parte, de edad que dixo ser de cinquenta y dos años, de offizio pintor, que vive en la calle de la Veronica en la plazeta de la Perera.

Preguntado si sabe o presume la causa porque ha sido llamado a este Santo Offizio, dixo que presume ha sido llamado para que diga y declare lo que ha visto y oydo dezir a Josepe Martinez del Notario, escultor de offizio, vezino de esta ciudad, que vive en su casa de este [al margen: afirmo el reo que era familiar], a qual ha oydo dezir en muchas y diferentes ocasiones que era familiar del Santo Offizio del districto de la Inquisicion de Logroño, y que tenia el titulo de tal, si bien este no se le ha visto.

[Al margen: Lo del encuentro con la justicia secular.] Item dize que oyo dezir al mismo Josepe Martinez que, encontrando una noche en esta ciudad a la justicia que yba de ronda y habiendole dicho que se tuviese al Rei, habia respondido que se tubiesen a la Inquisicion y les requeria se fuesen con el a hazer cierta diligencia por orden de este Santo Offizio en casa de cierta muger que $[f .6 \mathrm{v}$.] no nombro, ni adonde vivia, y haviendo traido los dichos ministros de justicia por diferentes calles de esta ciudad, ultimamente se havia entrado en casa de una muger que no nombro, ni dixo quien era, ni adonde vivia, y estando un rato bolbio a salir, aguardandole los dichos ministros de justicia a la puerta, a los quales dixo que no estaba en casa la dicha muger, y los despidio diziendoles que se fuesen con Dios, con lo qual se fueron.

Preguntado si dixo en essa ocasion o en otra quienes eran los ministros de justicia con quien paso lo sobredicho, dixo que el dicho Josepe Martinez no le dixo 
quienes eran ni como se llamaban y que todo lo dicho passo delante de dos criados de este, que el uno se llama [subrayado en el original: Juan] de nombre propio, y no le sabe el apellido, que ahora actualmente le tiene en su servicio, y el otro se llamaba [subrayado en el original: Agustin] de nombre propio que tampoco le sabe el apellido que entiende esta ahora en la villa de Madrid.

Item dize oyo dezir [subrayado en el original: a la muger] de Sebastian de Ruesta, ensamblador, que vive junto al convento de Santa Fe de esta ciudad, [al margen: hacia alarde de ser ministro del Santo Officio porque le estimasen] frente al Meson de la Alfondiga, que estando en su casa el dicho Josepe Martinez que vivia y trabajaba en ella entonzes, un dia sin dezir qual era, habia dicho delante de sus criados y gente de su casa, que ellos no sabian a quien tenian en ella, y que habian de saber tenian un familiar del Santo Offizio.

[f. 7] Item dixo que oyo dezir al mismo Josepe [subrayado en el original: Martinez] delante del mismo Juan criado de este, que estando un dia de esta Quaresma en la plaza del Pilar havia dicho a uno que estaba vendiendo sardineta haviendo mucha gente $y$ hechandole un lienzo por cima de ella, le hechase en el una libra de sardineta porque era familiar del Santo Offizio y que el que la vendia se la havia dado con mucha humildad y mucho gusto.

Y que todo lo referido en razon de lo que le havia pasado con la justicia viniendo un dia este de fuera y entrando en su casa se lo estaba contando a [subrayado en el original: Bartolome Roberto, de offizio pintor,] vezino de esta ciudad, y el mismo Bartolome Roberto despues se lo refirio a este preguntandole este que era lo que le dezia y quien era el que estaba con el, y el dicho Roberto le dixo que le referia lo que havia pasado con la justicia en la forma que lo tiene dicho, y que era familiar y que tenia el titulo de tal en su portamanteo, si bien nunca se lo ha enseñado ni este le ha visto, y que la persona que estaba con el era un sastre cuio nombre y apellido no le dixo ni donde vivia.

Preguntado si le ha visto este traer el avito de familiar o hazer otra accion o cosa alguna como tal familiar dixo que no le havia visto traer el avito de familiar, si bien le ha dicho lo havia buscado en la Plateria y por no hallarle lo havia mandado hazer, ni le ha visto hazer ni dezir otra cosa mas de lo que tiene referido y $[f .7 v$. ] que esta es la verdad por el juramento que tiene hecho y para lo que entiende ha sido llamado, y que de el ni de otra persona no sabe otra cosa, y en ello se afirmo y haviendosele leydo su dicho, dixo que estaba bien escrito.

Y luego dixo oyo dezir al dicho Josepe Martinez habra cosa de dos meses poco mas o menos estando en su casa de este calentandose a la chiminea, no se acuerda este a que proposito ni con que ocasion, [al margen: afirmo que avia diez años que no se avia confesado, que avia estado preso por casado dos veces] [subrayado en el original: que havia diez años que no se havia confesado y que havia estado preso en la Inquisicion sin dezir en qual por casado dos vezes, y que havia salido libre y que la prision havia sido en dos ocasiones, que la primera se havia huido de la carzel y despues le havian alcanzado en la ciudad de Tudela de Nabarra], donde le havian tenido preso, y de alli le habian librado, y que era verdad, que el estaba casado con una vizcaina cuio nombre no dixo ni adonde vivia, con la qual le havian hecho casar por justicia teniendole preso sin dezir adonde, si bien este presume devia ser en Navarra por dezir el dicho Josepe Martinez muchas vezes que era natural de aquel Reino de un lugar junto a Pamplona que no nombro, y que por haber sido casado por fuerza [tachado: le parezia no era valido] no quiso consumar el matrimonio, y que despues se havia ydo a Madrid donde havia tenido amistad con una viuda, y haviendo vuelto a su tierra le escrivia la dicha viuda sin dezir como se llamaba, y poniendole el sobre escrito a mi marido Josepe Martinez, y el a ella respondia, a mi muger fulana, pero que no se havia casado con ella, sino que aquello [f. 8] lo hazian para disimular y por si alguno les cogia las cartas, y haviendoselas cogido en Navarra y sabiendo que estaba casado con la dicha vizcaina, y viendo escrivia a la viuda y ella a el como marido y muger, entendiendo estaba casado dos vezes, le denuncio a la Inquisicion [subrayado en el original: Juan de Espinosa], de offizio pintor, natural de esta ciudad, hijo de Espinosa el pretinero, que entonces estaba en la ciudad de Pamplona y ahora entiende esta, segun ha oydo dezir, en la de Calahorra, y por esso le havian prendido y pasado con el lo que tiene referido, y esta es la verdad y no tiene mas que dezir. Bolbiosele a leer y dixo que estaba bien escrito, por el juramento que tiene hecho y que en ello se afirmaba y lo firmo.

[Suscripción autógrafa: Juan Galindo de Medina.]

Paso ante mi, Juan Jaime Esporrin. 


\section{Documento no 2}

1631, diciembre, 9. Zaragoza

Sebastián de Ruesta, hijo de Francisca Pastor, viuda de Francisco de Ruesta, se afirma como aprendiz con Tomás Lagunas, ensamblador, carpintero y entallador, por tres años.

Archivo Histórico de Protocolos Notariales de Zaragoza, no 1905, Lorenzo Villanueva, 1631, ff. 797-798 v.

-Regesta recogida en LONGÁS LACASA, Mã Á.: Las artes en Aragón en el siglo XVII según el Archivo de Protocolos Notariales de Zaragoza. De 1631 a 1633. Zaragoza, Institución «Fernando el Católico», 2006, p. 145.

\section{/f. 797/ [Al margen: Affirmamiento.]}

Eadem die. Yo, Sebastian de Ruesta, mancevo, hijo legitimo y natu [f. 797v.] ral que soy del quondam Francisco de Ruesta y Francisca Pastor, conyuges, mis padres, habitante en la ciudad de Caragoca, de grado, et cetera, certificado, et cetera, me firmo por criado, aprehendiz y sirbiente con vos Tomas Lagunas, ensamblador, carpintero y entallador, vecino de la dicha ciudad, a vuestro oficio por tiempo y a tiempo de tres años continuos y siguientes, los quales principiaran a correr desde el presente dia de oy con las condiciones infradichas y siguientes:

Et primo es condicion que vos, dicho Thomas Lagunas, durante los dichos tres años seais tenido y obligado tenerme en vuestra casa y serbicio dandome de comer, vever, vestir y calçar, sano y enfermo, no excediendo la dicha enfermedad de un mes adelante i esto francamente y sin con [f. 798] tarme de ello cosa alguna, y que al fin de dichos tres años me hayais de dar y deis vos, dicho Tomas Lagunas, un vestido de paño de valor de quatrocientos sueldos jaqueses o si no veinte libras jaquesas en dinero o lo que mas querreis.
Et si yo, dicho Sebastian de Ruesta, me fuere de vuestra casa y serbicio i si me fuere de aquella, por cada un dia que faltare sin venir a ella haya de pagar y pague ocho dineros por cada un dia.

Et doy por fianca, tenedora y cumplidora juntamente con mi a la dicha Francisca Pastor, mi señora y madre, que presente esta, et cetera.

Et yo, Thomas Lagunas, que a lo sobredicho presente soy, accepto y recibo el dicho aprehendiz por el dicho tiempo y condicion y prometo y me obligo enseñarle el dicho mi oficio [f. 798v.] tanto y tan largamente quanto yo se y el podra aprehender.

[Cláusulas de escatocolo y consignación de testigos: Martín Pablo Villanueva, infanzón, y Jusepe Antonio Esparviel, escribiente, habitantes en Zaragoza.] 


\section{BIBLIOGRAFÍA}

AGULLó Y COBO, M.: "Manuel Pereira: Aportación documental", Boletín del Seminario de Arte y Arqueología, XLIV, 1978, pp. 257-278.

AZCÁRATE, J. Mạ de: "El escultor José Martínez", Archivo Español de Arte, XXII, 1949, p. 84.

BARTOLOMÉ GARCíA, F. R.: “Un Niño Jesús del círculo de Martínez Montañés en Vitoria", Ars Bilduma, 4, 2014, pp. 27-35.

: “Niños montañesinos en Álava”, Ars Bilduma, 5, 2015, pp. 45-63.

BOLOQUI LARRAYA, B.: voz "Ruesta, Los", en Gran Enciclopedia Aragonesa, Zaragoza, UNALI, 1981, t. XI, p. 2944.

BRUÑÉN IBÁÑEZ, A. I., CALVO COMÍN, Mạ L., y SENAC RUBIO, Mạ B.: Las artes en Zaragoza en el tercer cuarto del siglo XVII (1655-1675). Estudio documental. Zaragoza, Institución «Fernando el Católico», 1987.

BUSTAMANTE GARCÍA, A.: "El Santo Oficio de Valladolid y los artistas", Boletín del Seminario de Estudios de Arte y Arqueología, 61, 1995, pp. 455-466.

CARRETERO CALVO, R.: "Sonidos en la pintura barroca española", en RODRÍGUEZ, G., y CORONADO, G. (dirs.): Paisajes sensoriales: Sonidos y silencios de la Edad Media, Mar del Plata, Universidad Nacional de Mar del Plata, 2016, pp. 331-363.

CORDERO DE CIRIA, E.: “Notas sobre el escultor José Martínez, discípulo de
Martínez Montañés y colaborador de Pereira, procesado por la Inquisición", Archivo Español de Arte, 258, 1992, pp. 234-235.

CORDERO DE CIRIA, E.: "Proceso inquisitorial contra Gabriel Ximénez Donoso, pintor", Archivo Español de Arte, 266, 1994, pp. 171-173.

: "Arte e Inquisición en la España de los Austrias", Boletín del Museo e Instituto «Camón Aznar», 70, 1997, pp. 29-86.

CRIADO MAINAR, J.: La escultura romanista en la Comarca de la Comunidad de Calatayud y su área de influencia. 1589-1639. Calatayud, Centro de Estudios Bilbilitanos de la Institución «Fernando el Católico», 2013.

ESTEBAN LORENTE, J. F.: "Una aportación al arte provisional del barroco zaragozano: los capelardentes reales", en Francisco Abbad Ríos: a su memoria, Zaragoza, Departamento de Historia del Arte de la Universidad de Zaragoza, 1973, pp. 35-64.

FERNÁNDEZ ROJAS, M.: "El convento del Espíritu Santo de Sevilla, vulgo de los Menores, de la Orden de Clérigos Regulares Menores", Laboratorio de Arte, 19, 2006, pp. 195-214.

FONSECA COUTO GOMES PEREIRA, M. A. da (ed.): Obras do Barão do Rio Branco IV: questões de limites Guiana francesa segunda memória. Brasilia, Fundação Alexandre de Gusmão, 2012.

FRANCO LLOPIS, B., y RUSCONI, S.: "Sobre pinturas deshonestas, lienzos y naipes protestantes. Tres documentos inquisitoriales vinculados a la 
censura y tráfico de imágenes heréticas en el mundo hispánico del siglo XVI", Manuscrits. Revista d'Història Moderna, 33, 2015, pp. 97118.

GRANADOS BLASCO, Mạ del C.: Las artes en Aragón en el siglo XVII según el Archivo de Protocolos Notariales de Zaragoza. De 1637 a 1639. Zaragoza, Institución «Fernando el Católico», 2007. Disponible online en http://ifc.dpz.es/recursos/publicaciones/26/68/_ebook.pdf

GUTIÉRREZ PASTOR, I.: "Juan de Espinosa y otros pintores homónimos del siglo XVII", en Príncipe de Viana. Primer Congreso General de Historia de Navarra. Historia del arte, Anejo no 11, Pamplona, Gobierno de Navarra, 1988, pp. 209-228.

JODRÁ ARILLA, G.: Las artes en Aragón en el siglo XVII según el Archivo de Protocolos Notariales de Zaragoza. De 1634 a 1636, Zaragoza. Institución «Fernando el Católico», 2007. Disponible online en http://ifc.dpz.es/recursos/publicaciones/26/67/_ebook.pdf

LANASPA MORENO, Mạ Á.: Las artes en Aragón en el siglo XVII según el Archivo de Protocolos Notariales de Zaragoza. De 1616 a 1618. Zaragoza, Institución «Fernando el Católico», 2005. Disponible online en http://ifc.dpz.es/recursos/publicaciones/25/15/_ebook.pdf

LÁZARO SEBASTIÁN, F. J.: "El Capítulo Eclesiástico de Épila en el Archivo de Protocolos Notariales de La Almunia de Doña Godina", en Archivo Ducal de Hijar. Archivo Abierto, pp. 1-20. Disponible online en http://www.archivoducaldehijar-

archivoabierto.com/articulos/ad008.pdf

LONGÁS LACASA, Mạ Á.: Las artes en Aragón en el siglo XVII según el Archivo de Protocolos Notariales de Zaragoza. De 1631 a 1633.
Zaragoza, Institución «Fernando el Católico», 2006. Disponible online en http://ifc.dpz.es/recursos/publicaciones/25/76/_ebook.pdf

LLAGUNO Y AMIROLA, E.: Noticias de los arquitectos y arquitectura en España. Madrid, Imprenta Real, 1829, t. IV.

MARÍAS, F.: "El problema de los artistas conversos en el Siglo de Oro", en MATA INDURÁIN, C., y MORÓZOVA, A. (eds.): Temas y formas hispánicas: arte, cultura y sociedad, Pamplona, Servicio de Publicaciones de la Universidad de Navarra, 2015, pp. 241-262.

MARÍN FIDALGO, A.: El Alcázar de Sevilla bajo los Austrias. Sevilla, Guadalquivir, 1990, vol. 2.

MIGUEL LOU, G. de: Las artes en Aragón en el siglo XVII según el Archivo de Protocolos Notariales de Zaragoza. De 1619 a 1621. Zaragoza, Institución «Fernando el Católico», 2005. Disponible online en http://ifc.dpz.es/recursos/publicaciones/23/89/_ebook.pdf

PALLARÉS FERRER, Mạ J.: La pintura en Huesca durante el siglo XVII. Huesca, Instituto de Estudios Altoaragoneses, 2001.

PASTOR OLIVER, M. Mạ: El tribunal inquisitorial de Zaragoza, bajo el reinado de Felipe IV. Tesis de doctorado. Zaragoza, Departamento de Historia Moderna y Contemporánea de la Universidad de Zaragoza, 2010.

PINTO CRESPO, V.: "La actitud de la Inquisición ante la iconografía religiosa. Tres ejemplos de su actuación (1571-1665)", Hispania Sacra, vol. XXXI, no 61-64, 1978-1979, pp. 285-322. 
PULIDO RUBIO, J.: El Piloto Mayor de la Casa de la Contratación de Sevilla: pilotos mayores del siglo XVI. Sevilla, Centro Oficial de Estudios Americanistas de Sevilla, 1923.

RECIO MIR, Á.: "Aquella segunda fábrica que ha de estar en lo interior de la otra: Los proyectos de tabernáculo para el sagrario de la catedral de Sevilla y su realización efímera en 1662", Archivo Español de Arte, t. LXXVI, no 301, 2003, pp. 55-70.

: "La difusión de los modelos montañesinos del Niño Jesús: causas de una producción seriada", en RAMOS SOSA, R. (coord. y dir.): Actas del coloquio internacional el Niño Jesús y la infancia en las artes plásticas, siglos XV al XVII. IV Centenario del Niño Jesús del Sagrario, 1606-2006, Sevilla, Archicofradía del Santísimo Sacramento del Sagrario de la Catedral de Sevilla, 2010, pp. 261-288.

SÁNCHEZ GUZMÁN, R.: "El escultor Manuel Pereira (1588-1683)", Cuadernos de Arte e Iconografía, t. XVII, no 33, 2008, pp. 6-278

SIMÓN DÍAZ, J.: “La Inquisición de Logroño (1580-1600)", Berceo, 6, 1948, pp. 83-96.

URREA, J.: "Introducción a la escultura barroca madrileña. Manuel Pereira”, Boletín del Seminario de Arte y Arqueología, XLIII, 1977, pp. 253-268.

: "Cano y Pereira contrastados", en Symposium internacional. Alonso Cano y su época, Granada, Junta de Andalucía, 2002, pp. 339-347.

VELANDIA ONOFRE, D.: Hacia una teología de la imagen. Mística, oratoria y pintura en la España del Siglo de Oro. Tesis de doctorado. Barcelona, Universitat de Barcelona, 2014. 